\title{
Pinus halepensis Mill. crown development and fruiting declined with repeated drought in Mediterranean France
}

\author{
Girard François $^{1}$, Vennetier Michel ${ }^{1,2}$ a, Guibal Frederic ${ }^{3}$, Corona Christophe ${ }^{3}$, Ouarmim Samira ${ }^{1}$ and \\ Herrero Asier ${ }^{4}$ \\ 1 - CEMAGREF, Ecosystèmes Méditerranéens et Risques, 3275 Route de Cézanne CS 40061, Aix en \\ Provence, France 13182 Cedex 5. \\ 2 - ECCOREV FR 3098, Aix-Marseille University, Aix-en-Provence, France \\ 3 - IMEP - Faculté des Sciences de St Jérôme, Avenue Escadrille Normandie-Niemen - Boite 441. F \\ 13397 Marseille cedex 20 \\ 4 - Departamento de Ecología. Facultad de Ciencias. Campus de Fuentenueva . Universidad de \\ Granada. 18071 Granada, España
}

a-Corresponding author: Michel Vennetier

Tel: (+33) (0)4.42.66.99.22 Fax: (+33) (0)4.42.66.99.23

Email: michel.vennetier@cemagref.fr

Keywords: Pinus halepensis; Primary growth; Shoot length; Branching rate; Needle number; Needle length; Polycyclism; Fruiting; Ring width; Tree architecture; Climate change; Mediterranean forest; Drought

\begin{abstract}
The objectives of this study were to describe and quantify Aleppo pine aerial primary growth processes and to assess their relationships with climate. Primary growth (branch length growth, branching rate, polycyclism, needle number and size, fruiting), i.e. crown development and reproduction, was reconstructed for the last 16 years in Mediterranean France. From 1998 to 2007, climate has been far hotter and drier than normal in South-eastern France. All variables related to crown development and fruiting, as well as radial growth, significantly declined after 2003 heat-wave and during repeated droughts from 2004 to 2007. A partial recovery of most parameters occurred from 2008 to 2010 on vigorous branches while frail branches showed less improvement. The limited crown development during unfavourable years may significantly hold back tree potential photosynthetic biomass for several following years and contribute to a slower than expected recovery of tree growth or to delayed die-back.
\end{abstract}

\section{1 - Introduction}

In the Mediterranean basin, summer drought is the main constraint on tree growth with great interannual variations in duration and intensity (Le Houerou, 2005). For the $21^{\text {st }}$ century, climate models predict in the Mediterranean basin a faster warming than in most other areas in the world, associated with a reduction of rainfall during the growth season (Gibelin and Deque, 2003; HesselbjergChristiansen and Hewitson, 2007). In addition, extreme climatic events, such the 2003 scorching heat, are prone to be recurrent (Meehl and Tebaldi, 2004). The response of forests to the forecasted increase in drought occurrence is considered a key issue in climate change scenarios (Hesselbjerg-Christiansen and Hewitson, 2007). Rapid decline in precipitation and higher temperatures are already noticeable in some areas in the Mediterranean basin giving a foretaste of the mid $21^{\text {st }}$ century climate. In Southeastern France, very low rainfall were observed each year from 2003 to 2007 (Météo-France, 2011). Moreover, ten of the twelve hottest years since 1850 were recorded between 1997 and 2008 (Vennetier and Ripert, 2009). The mean annual and mean summer temperatures of years 1998-2007 were respectively $0.9^{\circ} \mathrm{C}$ and $1.3^{\circ} \mathrm{C}$ over the average of the previous 30 years, while spring and summer rainfall were reduced from $18 \%$ and $32 \%$ respectively during this decade. 
Common in the Mediterranean areas with nearly 3.5 millions hectares, Aleppo pine (Pinus halepensis Mill.) shows an exceptional plasticity, growing on any substrate and on poor soils. Being thermophilious and heliophilous, it tolerates high temperatures but fears excessive humidity, frost and snow (Nahal, 1962; Vennetier et al., 2010). Aleppo pine strategy towards drought is to avoid water stress by closing precociously its stomata (Borghetti et al., 1998). Despite their adaptation to unstable climatic and edaphic conditions, some of Aleppo pine growth processes may have been negatively impacted by repeated dry and warm years. In Tunisia, El Khorchani et al. (2007) showed that, after 1978, frequent droughts significantly reduced its radial growth and increased mortality. Similar observations were made after year 2003 in southern France (Vennetier and Ripert, 2010). These results are consistent with models and long term observations showing that Aleppo pine growth is expected to suffer from changes in timing and duration of drought, particularly in spring and summer (Borghetti et al., 2004; Ogaya et al., 2003; Rathgeber et al., 2000; Sardans and Peñuelas, 2007; Vila et al., 2008).

Relationship between Aleppo pine radial growth and climate variability were well established in Mediterranean France (Nicault et al., 2001; Rathgeberet al., 2000; Rathgeber et al., 2005). On the other hand, except for tree height, scant literature exists on the relationship between primary growth processes and climate, whatever the species. Primary growth corresponds to the creation of new tissues outside existing organs, and includes bole, branch and root length growth, branching processes (birth of new branches or roots), creation and growth of leaves or needles and rootlets, flowering and fruiting (Barthelemy and Caraglio, 2007; Halle et al., 1978). By contrast, secondary growth for trees corresponds to the radial growth of existing branches and roots. Aleppo pine is commonly polycyclic (Girard et al., 2010): when adult, it is known to produce up to four annual growth units on vigorous branches: one or two, more rarely three, from late winter to the beginning of summer and sometimes one after summer drought (Debazac, 1963; Serre, 1976). An increased number of annual growth flushes means more ramifications and needles, longer shoots and higher primary production (Barthelemy and Caraglio, 2007). Impact of successive droughts such as the period 2003-2007 in southern France had radical impact on Scots pine (Pinus sylvestris L.) primary and secondary growth (Thabeet et al., 2009). Indeed, a sharp fall of ring-width, shoot length, branching rate, fructification and needle length was observed.

Aleppo Pines have serotinous cones that take three years to mature. Seeds can be stored and protected in the canopy for as long as 15-30 years (Nahal, 1962). Such a long lasting aerial seed bank is an adaptation to the pioneer status of this species, and is devoted to regeneration after wildfires. But the long maturation process makes each annual cone generation dependant on several years, and a cone deficit during one or several years have long lasting delayed effects on the reproduction potential. Climate change and a higher frequency of climate accidents should make Aleppo pine regeneration more uncertain,

The objectives of this study were (1) to describe Aleppo pine aerial primary growth processes (including cone production) and (2) to compute relationships between climate and tree primary and secondary growth over the last 15 years in Mediterranean France.

\section{2 - Materials and methods}

\section{1 - Study site}

The study took place in the Departmental Forest of Font-Blanche $\left(43^{\circ} 14^{\prime} 25^{\prime}\right.$ ' $\mathrm{N}, 5^{\circ} 40^{\prime} 40^{\prime \prime} \mathrm{E}$, altitude $425 \mathrm{~m}$ a.s.1.) in Provence, South-eastern France (Figure 1). Climate data were interpolated as a function of altitude $\left(0.6^{\circ} \mathrm{C} / 100 \mathrm{~m}\right)$ and distance from four stations of French National Meteorological Survey Network (MétéoFrance, 2009), located near the experimental site $(5-10 \mathrm{~km}$, altitude difference less than $200 \mathrm{~m}$ ). The climate is Mediterranean, characterized by a severe drought lasting usually two months in summer, but regularly three to four months, mild and humid winters, and a very low cloudiness. At this site, mean annual temperature and precipitations are $13.2^{\circ} \mathrm{C}$ and $695 \mathrm{~mm}(1979$ 2010). They were respectively $12.7^{\circ} \mathrm{C}$ and $745 \mathrm{~mm}$ for the period 1961-94 (Figure 2). Years 2003 to 2007 were characterized by the longest drought ever recorded (since 1860), with annual rainfall 20 to $60 \%$ under the average, and particularly a 50 to $60 \%$ yearly deficit of cumulated rainfall from January 
to August. Moreover, this period started with the 2003 scorching heat and ended in 2007 by the driest 12 -month period ever recorded $(281 \mathrm{~mm})$. At the end of 2003 summer, trees were severely defoliated and in very bad health conditions (Vennetier et al., 2007) as in most European forests (Zaitchik et al., 2006). 2006 and 2004 were marked by a terrible spring drought, lasting from February to July. Annual rainfalls of years 2008 and 2009 were normal but the summer drought of these years lasted four months. 2010 rainfall were $10 \%$ under the average but the summer drought was limited to 2 months and significant rains occurred up to the end of June. 2010 can be considered as the only normal year since 2003 .

Figure 1, Location of the study area in southern France. Grayscale colors represent altitude whereas black zones represent main towns.

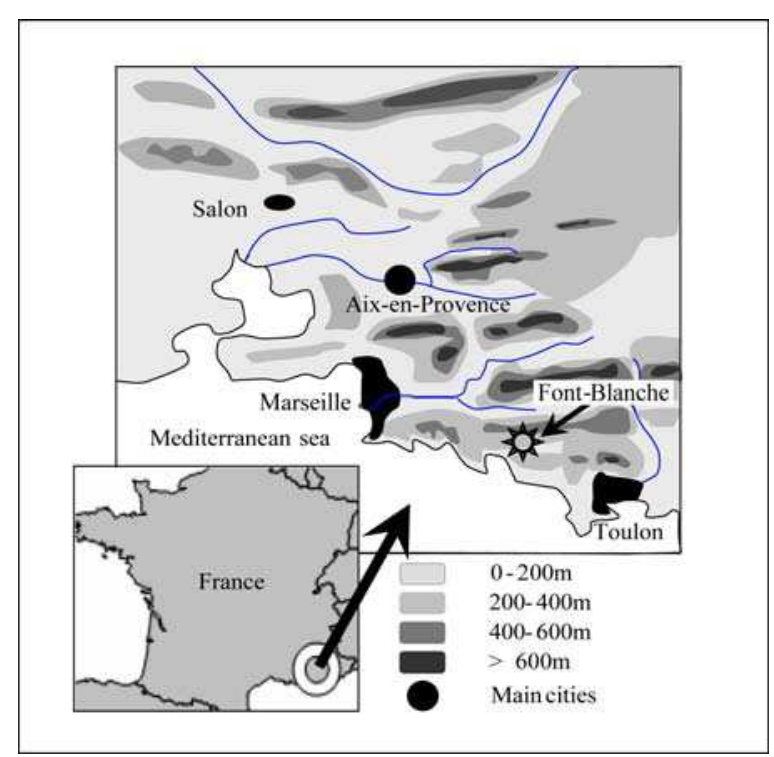

Two heavy snow falls severely damaging Pinus crowns were recorded recently, mainly in January $2001(30-60 \mathrm{~cm}$ in a few hours) and to a lesser extent in December $1998(15-35 \mathrm{~cm})$. The site is flat. The limestone-based shallow alteritic soil $(10-30 \mathrm{~cm})$ is characterized by $\mathrm{pH}$ close to seven, good nutrient content and high percentages of coarse fragments and rock outcrops. Stand productivity depends on penetrability of superficial bedrock for root extension. The Font-Blanche forest is dominated by irregular stands of 12-14 m high Aleppo pines aged between 35 and 115 years (dominant class $=55$ years), mixed with a six meters-high Quercus ilex L. coppice. The understory is a dense thicket, 1-3 $\mathrm{m}$ in height, of Quercus coccifera L. and Phyllirea latifolia $\mathrm{L}$. According to the bioclimatic index (BI) designed by Vennetier et al. (2008), site conditions and water balance at FontBlanche $(\mathrm{BI}=8)$ are very close to the mean value for the French Mediterranean area (BI span $=-80$ to +80 , mean $=0$ ). Accordingly, the site index for Aleppo pine calculated from tree height/age ratio is

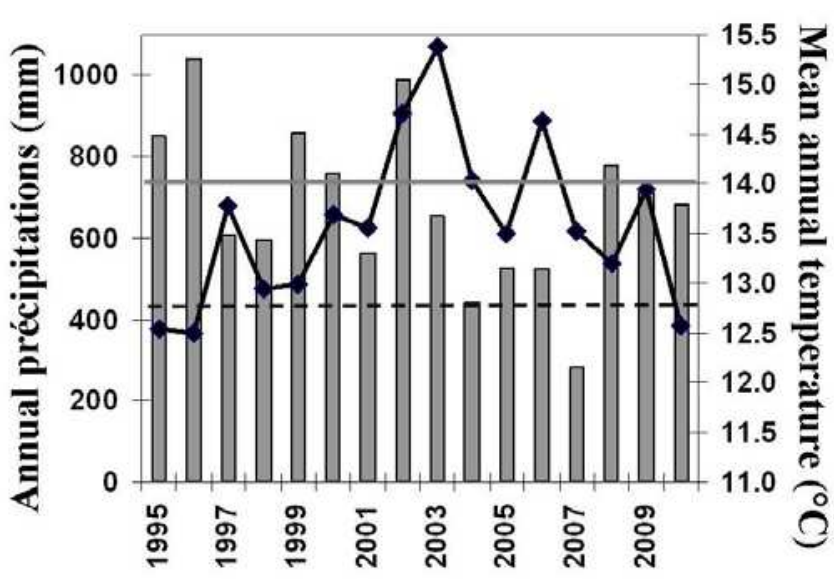
exactly in the middle of the average fertility class for this species in France (Vennetieret al., 2010). Font-Blanche site can therefore be considered as highly representative of French Aleppo pine stands.

Figure 2, Average annual precipitations (bars) and temperatures (black line) in FontBlanche since 1995. Horizontal lines are 1961-2008 averages: doted line $=$ mean temperature, grey line $=$ mean rainfall) .

\section{2 - Sampling}

Data were collected in a homogeneous experimental plot (2.25ha) from 2005 to 2010. Pairs of dominant branches (exposition in the crown: north and south) were cut on 42 dominant 58 year-old Aleppo pines. These pairs were cut at three crown positions per tree: top, intermediate and low-level, aged respectively 15, 25 and 35 years. Successive branch sampling from 2005 to 2010 (seven trees per year) was made to consider branch and axes autocorrelation and expand the studied time span. Sampled trees and branches were chosen for a low level of competition with neighbouring trees. 
Morphological markers like size and density of scales at the base of the growth units, lateral axes, and position of cones were used to reconstruct tree primary growth for the last 15 years on each branch, following methods described by Sabatier et al. (2003) and Pardos et al. (2003) which proved to be relevant for Aleppo pine. Crossdating of several secondary axes, and in some cases annual growth rings, were used to confirm the age of segments. In addition to measurements on branch principal axis, two pairs of secondary axes (one strong and one weak in each pair) were sampled: one pair 10 yearold and the other pair 5 year-old. At first, twigs were classified within each branch as function of their status: principal (P) (main axis), strong secondary axis (S-Strong) and weak secondary axis (S-Weak) (Figure 3). The status is based on relative diameter and length growth on each branch and not related to absolute vigour. Then, we classified twigs according to their absolute vigour, independently of their origin, status and position, To do so, twig length of years 2003-2005 (period common to all samples of the first period) was calculated and values were split into three groups of equal span (Figure 5C): frail twigs (annual growth $\leq 70 \mathrm{~mm})$, medium vigour $(71-140 \mathrm{~mm})$ and vigorous $(\geq 141 \mathrm{~mm})$. Twigs were further distributed into theses groups according to the mean length of years 2003-2005

Figure 3, Schematic representation of shoot sampling. Principal axis, $S$-Weak and S-Strong axes of five years-old and those of 10 years-old are represented (Girard et al., 2010).

A weekly follow-up of branch primary growth was performed from scaffoldings for 16 additional trees from January 2008 to December 2010, with exactly the same protocols than on cut branches. On these trees and on cut branches of 6 other trees, the proportion of shoots bearing male flowers as well as the length of male flowers on these shoots were measured retrospectively for years 2007-2010. On young shoots, the scars of male flowers, characterized by a prominent curved scale, are easy to differentiate from flat needle scars.

\section{3 - Growth reconstruction and measures}

Analysis of the number and length of flushes per annual shoot and total shoot length were used to elaborate master chronologies between 1995 and 2010 for each crown level and axes status. The 16year period for retrospective analysis was chosen because structural information disappears with time due to (1) the natural fading of morphological markers and/or (2) the natural self-pruning of twigs. Length of each growth units was measured using a calliper electronic ruler $( \pm 0.1 \mathrm{~mm})$. Along with morphological markers identification, number of ramifications, number of living and aborted cones and number of needles were counted per growth unit and then bulked per year. Only fully developed cones were considered for fruiting rate, aborted cones being analyses separately. As Aleppo pine usually keeps its needles between two and four years on adult trees, living needles were directly counted on each growth unit of the two last years. For older years, fascicles scars were counted following the spiral arrangement when visible, and living needles were counted when present to assess the proportion of survival in the third and fourth year. As for other pines species, needle fascicles are generally arranged in three to five spirals along the shoot. Counting needles on one or two spirals and then bulking the count for the number of spirals proved to be a very reliable assessment (error $<2 \%$ ) (Jalkanen et al., 1994, 1998). Needle length was measured with the same electronic ruler than shoots $( \pm 0.1 \mathrm{~mm})$ and averaged on 10 needles per growth unit, regularly sampled from its base to its end all around the twig. In case of polycyclism, for a given axis, annual needle length was obtained by the mean of all growth units weighed by the number of needles per unit. We also assessed the normal needle length of Aleppo pine in the study area. We averaged the values of all specimens collected close to the study area in similar site conditions and preserved in the herbarium of Provence University at Marseille (L. Samat; H. Roux, P. Blancand general herbarium): from 8 sites sampled from 1834 to 1921, 26 twigs and 41 growth units were measured, all of the last two years before the sampling date which was always in April to collect flowers. 
A weak tendency to branch growth slowing down with time corresponds to the normal ageing of branches and the progressive decline with increased competition by the top crown and neighbouring trees. This natural trend is described in literature (Barthelemy and Caraglio, 2007; Caraglio et al., 2007; Masotti et al., 1995) and can be assessed thanks to the successive branch sampling (2005-2009) and the sampling at three levels in the crown. As middle crown branches were chosen to be 10 years older than top branches, we can compare the growth of shoots of the extremity of top branches with 10 years older shoots of middle branches: they were, with a ten years interval, exactly in the same relative position in tree crown and in the stand. The same reasoning allows comparing the extremity of middle crown branches ( 25 years old) and 10 years older shoots of low crown branches ( 35 years old). As Aleppo pine height growth models for Southern France (Rathgeber et al., 2004; Vennetier and Hervé, 1999) indicate a linear trend and no change in tree height growth between 35 and 55 years, one can consider that the same position in the crown should lead to the same primary growth rate. This trend was calculated for each parameter.

\section{4 - Ring-width chronologies}

Two cores per tree were collected from all sampled trees at $1.3 \mathrm{~m}$ height. To construct radial growth curves by tree and for the Font-Blanche stand, ring widths of each core were measured using a Velmex micrometer (Velmex Inc., Bloomfield, N.Y.) $( \pm 0.002 \mathrm{~mm})$. Ring-width series were firstly crossdated visually and a second check was made using the statistical software COFECHA (Holmes et al., 1986). Each ring-width series was standardized using a 32-year cubic spline using the software package ARSTAN (Cook, 1985). The program was used with a double detrending; (1) a negative exponential or a straight line and (2) a cubic spline function with a $50 \%$ cutoff wavelength. The standardization process allows age related tendencies to be removed from the growth curve to obtain a homogenized variance. The resulting data consists of a dimensionless, standardized index with variations representing the effect of stress factors (climate, insect herbivory, etc.) on tree growth. Once ringwidth series were accurately crossdated and standardized, elementary series were averaged for each tree and master chronologies were constructed for Font-Blanche by averaging indexed tree series. Only the 1995-2010 period from these indexed series were used for the purpose of this study (see complete chronology in Figure 4).

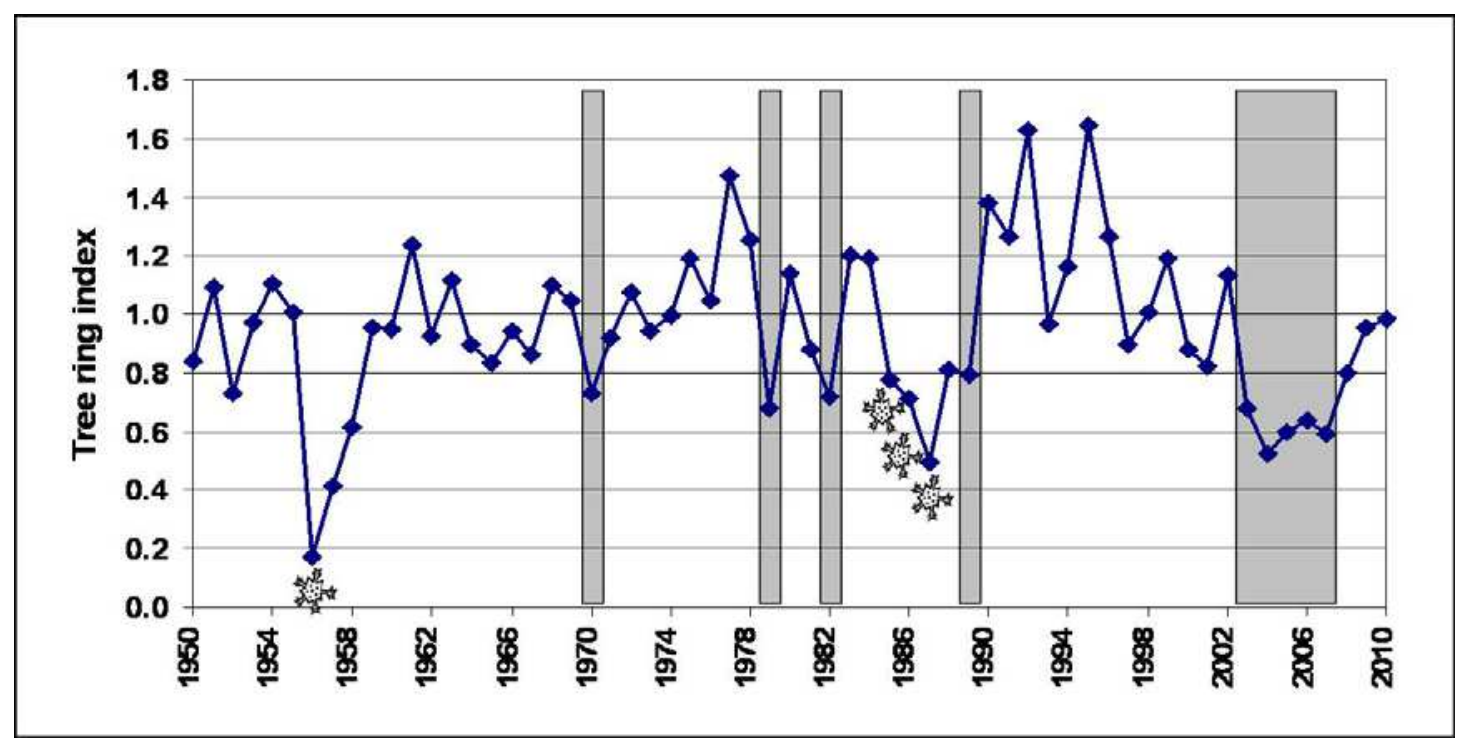

Figure 4, Aleppo pine tree-ring indexed chronology at Font-Blanche for the period 1961-2008. Gray periods represented severe drought and snowflakes represents severe frosts. 


\section{5 - Statistical analysis}

Statistical analyses were computed with ADE4 (Thioulouse et al., 1997) and R software (R Development Core Team, 2004). At first, a principal components analysis (PCA) was performed to provide an overall assessment of the role of time (year of measurement) and the correlation between ramifications $(\mathrm{Ra})$, fructification $(\mathrm{Fr})$, shoot length $(\mathrm{SL})$, number of needles, number of growth units $=$ number of cycles per year (GU) and ring width (RW) for the period 1995-2010 and for strong axes. Then, relationships between each of these variables and climate were investigated using a partial least square (PLS) regression. PLS regression was chosen because it handles many variables with relatively few observations (Cramer et al., 1988) and deals with correlated variables (Wold, 1995). The number of significant PLS components was chosen by a permutation test (Good, 1994) with a 5\% threshold for the explained variance. Variables were tested with a 1000-step cross-validation (Amato and Vinzi, 2003): they were retained only when the confidence interval $(p<5 \%)$ for their partial correlation coefficient excluded zero. Climatic monthly parameters tested in the regression were rainfall $(\mathrm{P})$, maximum temperature (MaxT), minimum temperatures (MinT) and mean temperatures (MT) from January of year (n-1) to November of year (n) over the period 1995-2010, according to the phenology of this species in South-eastern France (Orshan, 1989; Serre, 1976). The low number of observations (16) and high inter-annual variability of climate made grouping monthly climatic parameters necessary to obtain significant variables. We grouped the successive months having same signs for their individual partial correlation coefficients (sum of precipitations, average temperature). To compare exposition, position, status and vigour classes for each growth variable, normality was checked using a standard Shapiro-Wilks test. When the distribution was normal, a variance analysis and a multiple comparison test were performed to look for significant differences globally and further compare the different classes two by two. When the distribution was non-normal, these comparisons were performed respectively by a Kruskall-Wallis test and a Neymenyi test (Nemenyi, 1963)

\section{3 - Results}

For the period 1995-2010, the first PCA axis explained 58\% of the variance and was strongly correlated with the number of growth units, ramifications, shoot length, ring width and the number of needles (Figure 5). This axis was clearly related to primary and secondary growth. The second PCA axis explained $17 \%$ of the total variance and was correlated positively with fruiting and negatively with needle number. In the PCA plane, years were represented as observations which allowed discriminating three groups.

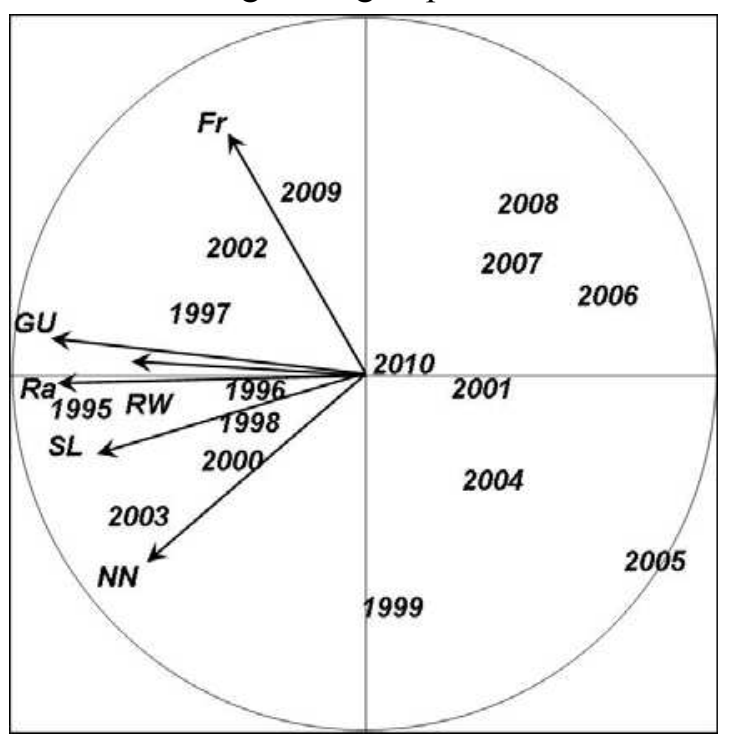

a) Years 2001 and 2004 to 2008 were characterized by poor radial and shoot growth and crown development, 2005 and 2006 being the worst.

b) At the opposite, 1995 to $1998,2000,2002$ and 2003, were good years for primary and secondary growth, 1995 and 2003 being the best.

c) 2009, followed by 1999 and 2010, allowed intermediate growth and crown development.

Among these groups, variations along axis 2 were due mainly to the differences in fruiting rate and secondarily to contrasted needle number. 2010 was very close to the middle of the plane.

Figure 5, PCA main plane (axes 1 and 2), 1995-2010 period, for every axes using six variables: ramifications (Ra), fructifications ( $F r)$, shoot length $(S L)$, number of needles (NN), number of growth units $(G U)$ and ring-width $(R W)$. The first two axes explained respectively 58 and $17 \%$ of the total variance. 
As a whole (figure 4 and 6), primary and secondary growth showed a deep trough after 2003, the worst years being generally 2005 and 2006, which is consistent with the position of these two years in the PCA plane. The recovery occurred progressively, beginning from 2007 to 2009 according to variables. It was mainly visible for ring width and for strong axes, for which 2009 and 2010 values rose again to pre-2003 levels, and to a lesser extent for medium vigour axes. Frail axes primary growth clearly dropped in 2004 and then remained stable at very low levels up to 2010, except for needle length.
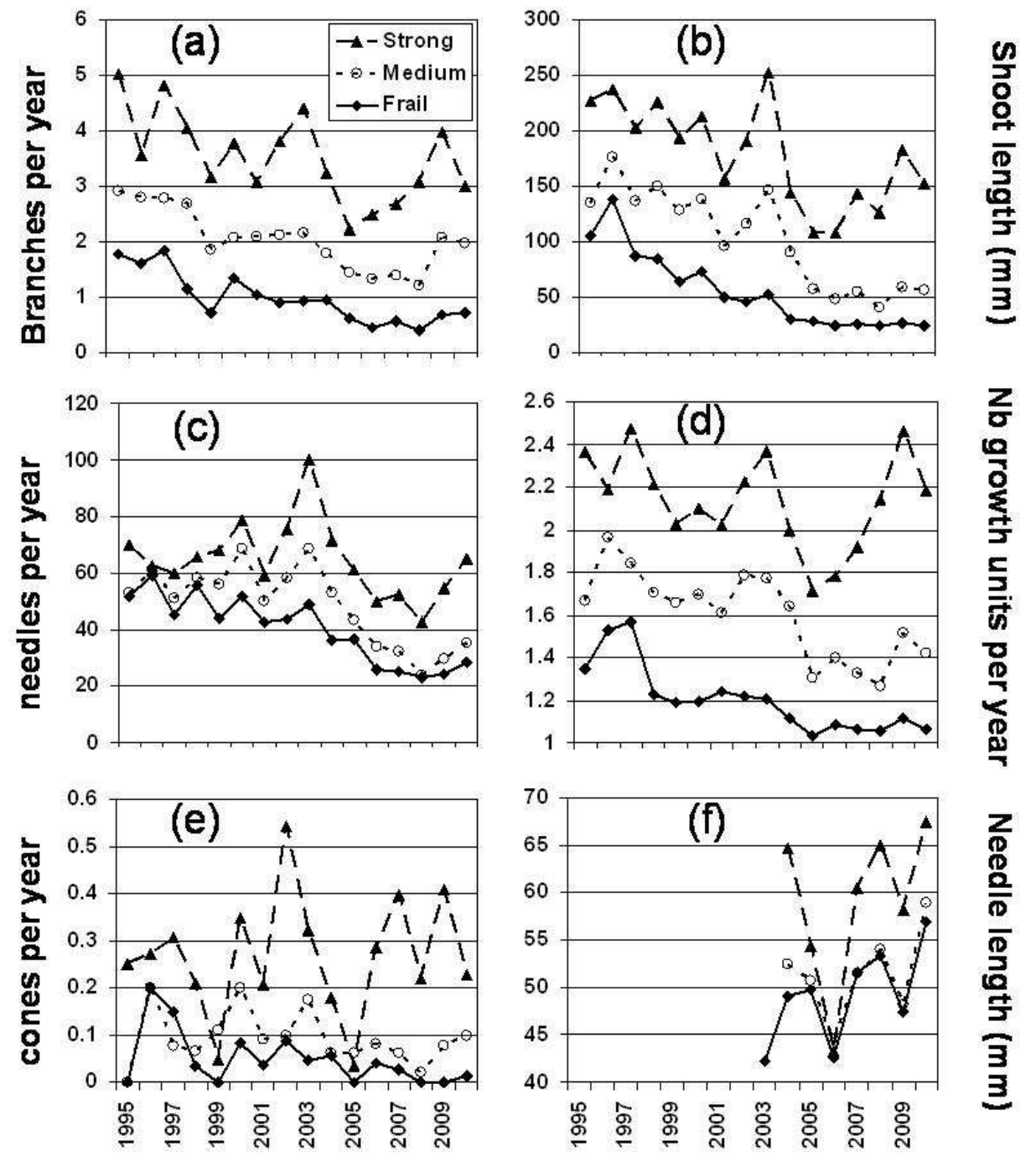

Figure 6. Annual number of branches (a), number of needles (b), fructification (c), shoot length (d) number of cycles (e) and needles length (f) as function of axe vigour (frail, medium, vigorous) at FontBlanche for the period 1995-2010.

Top-level, south-exposed, principal and vigorous axes were more ramified than low, north-exposed, weak and frail axes respectively. (Table 1 and Figure $6 a$ ). The number of ramifications peaked in 1995, 1997, 2003 and 2009 for vigorous axes, but these peaks did not appear on medium vigour and frail chronologies which interannual variations were far smaller. However, the low value of 1999 as well as the break after 2003 appeared for each vigour class. Vigorous axes branching rate progressively recovered from 2007 to 2010 . In opposition, medium axes, showed no sign of recovery before 2009 and frail axes no increasing trend after 2004. A significant decreasing trend was observed from 1995 to 2010 for vigorous, medium vigour and frail axes $\left(r^{2}=0.34,0.60\right.$ and 0.71 respectively for $p<0.01$ ). But there were no trend before 2004 nor from 1999 to 2010 for strong and medium vigour axes, showing that the global trend was mainly due to the break after 2003. 
Table 1: Differences in the number of branches, number of needles, fructification, shoot length, and number of cycles computed using a Neymeni test. Results are shown for axe position (low, middle, top), axe exposition (north vs south), axe status (principal, S-Strong, S-Weak) and axe vigour (frail, medium and Vigorous). Figures in bold correspond to significant differences (value superior to the Nemenyi threshold).

\begin{tabular}{cccccc} 
& $\begin{array}{c}\text { Number of } \\
\text { branches }\end{array}$ & $\begin{array}{c}\text { Number of } \\
\text { needles }\end{array}$ & $\begin{array}{c}\text { Number of } \\
\text { fructifications }\end{array}$ & Shoot length & $\begin{array}{c}\text { Number of } \\
\text { cycles }\end{array}$ \\
\hline Axe position & & & & & \\
Low $<$ middle & $\mathbf{3 . 2 8 1}$ & 0.224 & 0.608 & $\mathbf{3 . 8 6 7}$ & $\mathbf{2 . 7 8 2}$ \\
Low $<$ top & $\mathbf{5 . 8 6 6}$ & $\mathbf{4 . 2 6 7}$ & 0.736 & $\mathbf{7 . 2 0 5}$ & $\mathbf{6 . 5 9 2}$ \\
Middle $<$ top & $\mathbf{2 . 9 9 4}$ & $\mathbf{4 . 7 2 7}$ & 0.286 & $\mathbf{3 . 9 2 9}$ & $\mathbf{4 . 4 9 1}$ \\
Neymeni threshold & 2.394 & 2.394 & 2.394 & 2.394 & 2.394 \\
\hline Axe exposition & & & & & \\
North $<$ South & 0.001 & $\mathbf{3 . 9 1 2}$ & 0.343 & 0.521 & 0.262 \\
Neymeni threshold & 2.638 & 2.638 & 0.96 & 2.638 & 2.638 \\
\hline Axe status & & & & & \\
S-Weak $<$ S-Strong & $\mathbf{2 . 4 1 6}$ & $\mathbf{8 . 8 3 5}$ & $\mathbf{3 . 0 9 5}$ & $\mathbf{6 . 5 9 2}$ & $\mathbf{6 . 5 1 4}$ \\
S-Weak $<$ Principal & $\mathbf{6 . 9 6 8}$ & $\mathbf{6 . 2 1 1}$ & $\mathbf{5 . 1 4 7}$ & $\mathbf{4 . 0 6 1}$ & $\mathbf{4 . 2 0 5}$ \\
S-Strong $<$ Principal & $\mathbf{1 0 . 1 5 9}$ & 2.225 & $\mathbf{2 . 5 5 5}$ & $\mathbf{1 1 . 2 4 9}$ & $\mathbf{1 1 . 3 3}$ \\
Neymeni threshold & 2.394 & 2.394 & 2.394 & 2.394 & 2.394 \\
\hline Axe vigour & & & & & \\
Frail $<$ Medium & $\mathbf{6 . 6 8 4}$ & $\mathbf{4 . 8 9}$ & 1.423 & $\mathbf{4 . 6 3 8}$ & $\mathbf{4 . 8 8 1}$ \\
Frail $<$ Vigorous & $\mathbf{9 . 5 2}$ & $\mathbf{8 . 4 5 8}$ & $\mathbf{5 . 6 3 3}$ & $\mathbf{9 . 8 6 7}$ & $\mathbf{8 . 3 6}$ \\
Medium $<$ Vigorous & $\mathbf{3 . 8 6 7}$ & $\mathbf{4 . 1 3 8}$ & $\mathbf{4 . 1 8 3}$ & $\mathbf{1 2 . 8 3 1}$ & $\mathbf{1 1 . 9 2 2}$ \\
Neymeni threshold & 2.394 & 2.394 & 2.394 & 2.394 & 2.394 \\
\hline
\end{tabular}


Total annual shoot length followed globally the same patterns than the branching rate and showed the same differences between classes of position, status and vigour (Table 1 and Figure 6b). However, medium vigour axes did not recover after 2004 and remained at a very low level close to that of frail axes up to 2010. A significant decrease occurred since 1995 whatever the position, the exposition or the status. When standardized, all shoot length chronologies followed a very similar pattern, with maximal values in 1996, 1998, 2000 and 2003, and an abrupt fall after 2003 with a minimum in 2005 and 2006. Except for frail axes, victims of a first break in 1998, no trend could be seen before 2003.

The number of needles (Table 1 and Figure 6c) was different between all vigour classes, and also between position and status classes except for low vs middle crown and S-Stong vs Principal axes. At the opposite of all other primary growth variables, it was significantly different between north and south exposed branches. Needle number was stable up to 2003 for the three vigour classes. After a peak in 2003, particularly pronounced on strong axes, it dropped sharply to reach the lowest value in 2008. It increased for the three vigour classes in 2009 and 2010, but rose again to pre-2003 values only for strong axes. Needle life-span was longer on weak and medium vigour axes (respectively $45 \%$ and $25 \%$ of shoots with 3 year-old needles) than on vigorous axes (10\%), the proportion of surviving needles for weak and medium vigour twigs in the third year being highly variable (average $40 \%$, median 30\%, range 5-100\%). A small proportion of frail axes (8\%) kept part of their needles 4 years.

The number of growth units was significantly different at each position, for each status and for each vigour class: high, principal and vigorous axes produced more cycles than low, weak and frail axes respectively (Table 1 and Figure 6d). For the period 1995-2010, the number of growth units followed exactly the same trends as the number of branches and peaked at the same time, with only two slight differences: (i) the recovery was a bit faster for the number of growth units on vigorous axes, reaching pre-2003 values since 2008 and a peak equivalent to the maximum values of 2003 and 1997 in 2009; (ii) the drop of the number of growth units after 2003 on medium vigour axes was more abrupt and the loss more important. Since 2005, frail axes are almost only monocyclic, and each year only two fifth of medium vigour axes are polycyclic (maximum 2 cycles). The increasing number of growth units from 2008 to 2010 come mainly from late polycyclism appearing in October or November, and giving very short shoots $(5-20 \mathrm{~mm})$ often needleless or with abnormally short needles $(4-20 \mathrm{~mm})$.

Fructification was found on the most vigorous axes and particularly on principal axes (Table 1 and Figure 6c), mainly in the top and middle of the crown up to 2003 and after 2008, but only in the top canopy from 2004 to 2008. Medium vigour and S-strong axes give three to four times less cones per year than vigorous and principal ones, and nearly only in the top crown. However, due to the high variability and generally low values, no significant difference was found between top, middle and low crown whatever axes vigour and status. Frail axes nearly never give female flowers. In many cases from 2003 to 2007, medium vigour axes which gave a cone became frail as they were unable to feed both the cone and the shoot. No general pattern of fruiting was found at Font-Blanche. On vigorous axes, minimum values were observed in 1999 and 2005, with breaks following 1998 and 2003, lasting one and two years respectively, and peaks in 1997, 2000, 2002 and 2007 and 2009. Medium vigour and frail axes follow the same pattern. Cone abortion rate reached its maximum during the 2003-2006 period (40-60\%), and remained high (20-40\%) except on the most vigorous axes up to 2008.

The average needle length at Font-Blanche since 2003 was $57.6 \mathrm{~mm}$, (SD $9.1 \mathrm{~mm}$ ) in the best case i.e. vigorous, principal and top crown axes (Table 2 and figure $6 f$ ). Maximum annual values $(67.5 \mathrm{~mm})$ were reached on these axes in 2010, slightly above the levels of 2004 and 2008 (65 mm). For medium and frail axes, needle length was shorter: $50.5 \pm 3.8 \mathrm{~mm}$ and $49.3 \pm 4.1 \mathrm{~mm}$ respectively. No retrospective study before 2003 was possible due to the short needle life-span on adult trees. This life span was particularly reduced for 2003 needles ( $<2$ years): none of them were found in spring 2005 on vigorous and medium vigour axes, a few ones remaining only on frail axes. Nevertheless, several observations were possible. The average needle length slowly increased from 2003 to 2010, with a relapse in 2006, this fall being more drastic on vigorous than on other axes. Samples from the herbarium of Provence University showed an average length of $73 \pm 17 \mathrm{~mm}$ as a whole. It ranged from $91 \pm 20 \mathrm{~mm}$ for main, vigorous and generally polycyclic twigs bearing female flowers $(7$ samples, 
mean annual shoot length $=105 \pm 33 \mathrm{~mm}$ ) and $65 \pm 11 \mathrm{~mm}$ for all other twigs, bearing male flowers and generally frail (no polycyclism, mean annual shoot length $=36 \pm 24 \mathrm{~mm}$ ). In Font-Blanche, average needle length for vigorous and frail axes with similar shoot length were respectively $35 \%$ and $25 \%$ smaller in the last six years, and even for the longest ones and the best years hardly reached the minimum value cited in all plant guides $(60 \mathrm{~mm})$ or measured in botanical collections $(65 \mathrm{~mm})$.

Table 2: Mean needles length per year at Font-Blanche between 2003 and 2010.

\begin{tabular}{ccccccc} 
Year & \multicolumn{2}{c}{ Frail } & \multicolumn{2}{c}{ Medium } & \multicolumn{2}{c}{ Vigorous } \\
\hline & $\begin{array}{c}\text { Mean } \\
(\mathrm{mm})\end{array}$ & $\begin{array}{c}\text { Std. Err } \\
(\mathrm{mm})\end{array}$ & $\begin{array}{c}\text { Mean } \\
(\mathrm{mm})\end{array}$ & $\begin{array}{c}\text { Std. Err } \\
(\mathrm{mm})\end{array}$ & $\begin{array}{c}\text { Mean } \\
(\mathrm{mm})\end{array}$ & $\begin{array}{c}\text { Std. Err } \\
(\mathrm{mm})\end{array}$ \\
\hline 2003 & 42.2 & 4.5 & & & & \\
2004 & 49.1 & 9.0 & 52.5 & 7.9 & 64.7 & 6.7 \\
2005 & 49.8 & 7.7 & 50.7 & 8.0 & 54.4 & 11.2 \\
2006 & 42.6 & 6.1 & 44.1 & 7.4 & 43.3 & 6.9 \\
2007 & 51.6 & 7.7 & 51.5 & 7.0 & 60.5 & 7.4 \\
2008 & 53.4 & 10.4 & 54.0 & 10.9 & 65.1 & 12.9 \\
2009 & 47.5 & 8.1 & 48.2 & 6.5 & 58.2 & 6.8 \\
2010 & 56.9 & 7.8 & 59.0 & 10.8 & 67.5 & 9.6 \\
\hline
\end{tabular}

Figure 7 shows the relationships between shoot length and climatic variables (total monthly precipitation and mean monthly temperature) for vigorous shoots. Medium vigour and frail shoots as well as other position and status classes where investigated and showed very similar patterns. However, PLS regression models and climatic variables were sometimes less significant.

Figure 7, Significant climate parameters $R^{2}$ and $p$ values in PLS regression (one significant component) for shoot length on vigorous axes. Successive months having same signs for their individual partial correlation coefficients were grouped (sum of precipitations, average temperature). Minus signs (-) stand for months of the preceding year and the '+' stands for months of the current growing year. Prec: monthly precipitations; MT: mean monthly temperatures.

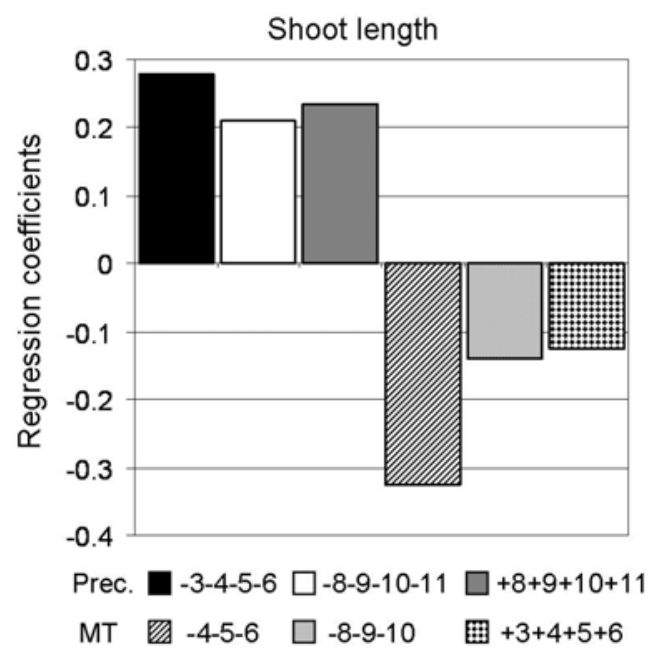

Figure 8 presents the significant explanatory climate variables in the PLS regressions for all studied parameters. Globally, except partially fructification, the response of secondary and primary growth parameters is always positive to rainfall and negative to temperature. Significant climatic variables can be grouped into five periods: rainfall and temperature preceding and accompanying bud formation before the summer drought of previous year (year [n-1]; period 1) are critical for all parameters but fructification, as are rainfall of august and fall [n-1] (period 2). Temperatures of this second period influence mainly growth parameters and less branching rate. Winter rainfalls as a whole (period 3) increase the number of growth units of the following year. February rainfalls influence ring width and fructification. Spring rainfalls of current year (period 4) are important for ring width and fructification, and spring temperature for shoot elongation. Finally, rainfall of period 5 including august and fall of year [n] act upon all growth parameters. Ring width responds to temperatures of this last period. Overall, the dominant role of climatic conditions of the previous year [n - 1] for primary growth, particularly rainfall but also mean temperature, must be underlined. Previous year is as important as present year for crown development. 


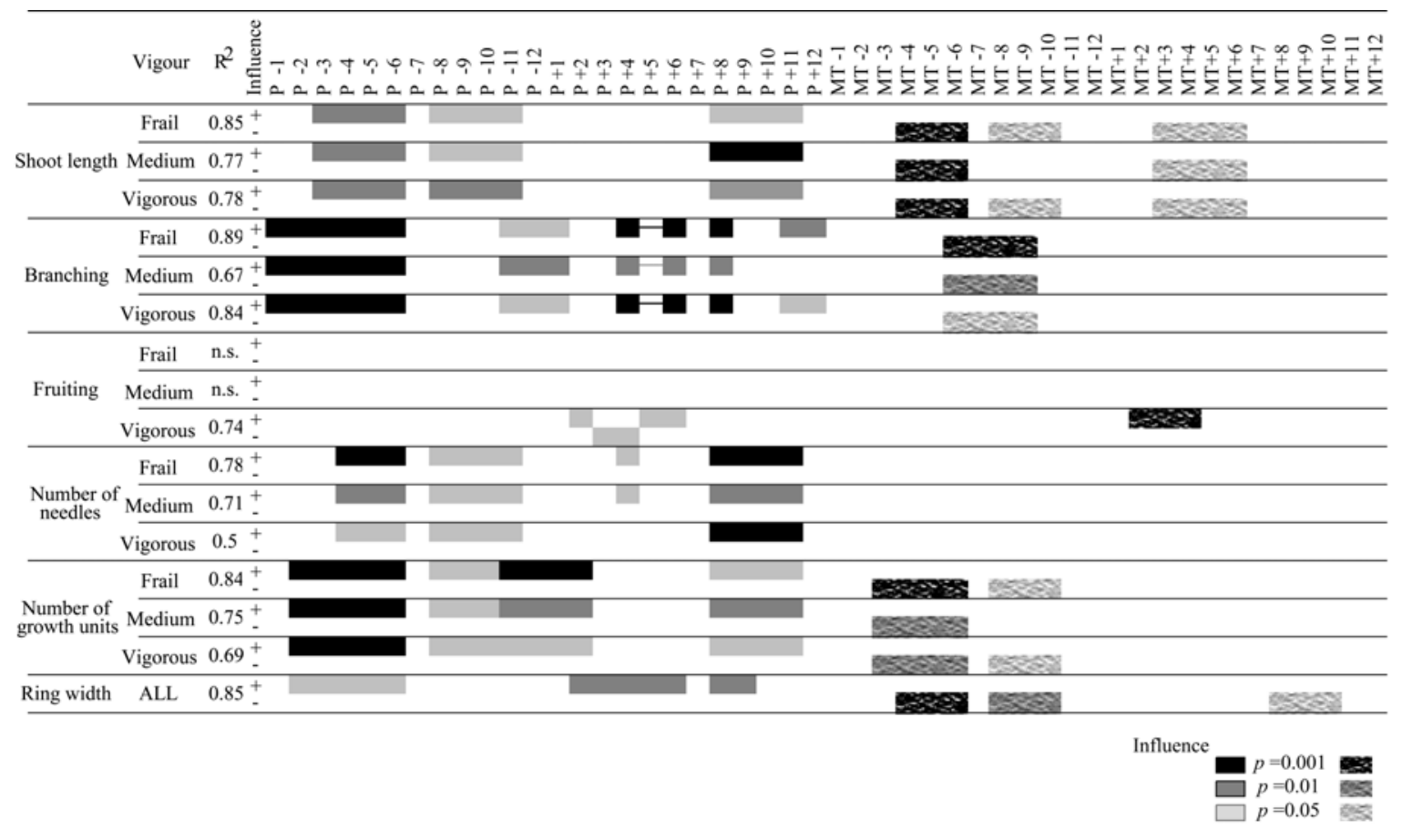

Figure 8, Significant climate parameters $R^{2}$ and $p$ values in PLS regression (one significant component) for shoot length, ramifications, number of needles, number of growth units, fructifications and ring-width on frail, medium vigour and vigorous axes. Black squares are significant at $p=0.001$, dark grey at $p=0.01$ and light grey at $p=0.05$. Signs $(+$ or -$)$ indicate a positive or a negative relationship. $P$, precipitation, MT, mean temperature.

The rate of male flowering from 2007 to 2010 was respectively $32 \%, 42 \%, 60 \%$ and $41 \%$ of all measured twigs. The length of male flowers on twigs was respectively $3.7( \pm 1.6), 5.3( \pm 2.0), 7.1$ $( \pm 2.6)$ and $7.7( \pm 3.8) \mathrm{mm}$. It was each year $15 \%$ longer for S-strong and principal axes than on SWeak and frail twigs, reaching up to $25 \mathrm{~mm}$ on secondary axes of the middle and top crown. In the low crown, male flowers appeared mainly on the principal axes and on vigorous secondary twigs. In the top crown, male flowers developed mainly on secondary and medium vigour twigs. In the middle of the crown, male flowers appeared on any shoot except the most vigorous, generally devoted to female flowers. The less vigorous twigs rarely gave male flowers, except in 2009. The exceptional male flowering rate in 2009 was due to the fact that many S-strong shoots of the top crown flowered, as well as frail shoots of the low and middle crown.

The natural trend of decrease of the parameters with age proved to be weak for branch length growth (30 mm/10 years) and branching rate $(0.45 / 10$ years), and non significant for the other variables. For the 16 studied years, all observed trends were sharper than the natural one. For shoot length, observed values were $15-40 \%$ under the natural trend during the 2004-2007 period

\section{4 - Discussion}

\section{1 - Relationship between primary growth and climate}

The PCA plane showed that Aleppo pine primary and secondary growth severely suffered from an exceptionally dry and hot period from 2003 to 2007 in southern France. Shoot length, number of growth units and branching rate are closely interrelated explaining partly why they appeared clustered on the PCA plane. They are also correlated with needle number. Indeed, each new cycle for a given year on a branch adds length, new branches and usually needles. These four parameters showed the same decreasing patterns after 2003 and partial recovery from 2007 to 2010. Although the series is shorter, the trend of needle length is consistent with the general trend of previous parameters, with low values from 2003 to 2006 and a significant recovery from 2007 to 2010. Our PLS results suggest that 
high water availability whatever the season in previous and present year improves tree health and vigour and therefore primary growth, through the induction of many cycles in buds or their elongation. Abundant winter rainfall specifically improves tree health condition at the beginning of the following growth season (Borchert, 1994) and helps the development of spring flushes, and probably the induction of later flushes. The earlier water stress is released at the end of summer, the longer and more developed the late flush. In the last 12 years, drought generally lasted up to the middle or the end of September. Thanks to very high temperatures in fall, late polycyclism occurred after 2007 but rarely before mid or end of October (Vennetier et al., 2011), too late for the shoots to fully develop and bear significant needles. From 1995 to 2000 and in herbarium samples, most of late flushes are short but bear normal needles. At Font-Blanche, the higher number of growth units after 2008 compared to previous years comes from such late flushes, increasing at the same time branching rate. Despite an additional flush, the 2008 total shoot length is shorter than in 2007, as this late flush was unfinished. This poor growth performance in 2008 is probably the delayed impact of 2007 drought, added to a severe (four months) and early summer drought in 2008. The correlation between number of growth units and annual shoot length which was good in the past should decrease in the future due to recurrent delayed late flushes, as already observed in 2009-2010, shoot length increasing slower than the number of growth units.

The slow recovery or stagnation of needle number and shoot length for medium vigour axes in 20072010, compared to strong axes, may be partly due to the increasing male flowering rate and length. At the base of the first annual flush, each male flower takes the place of a needle, so that the higher the flowering rate and the flowering length, the fewer needles are formed on a given tree or shoot. Moreover, male flowering uses a lot of resources, so that flowering shoots are usually monocyclic (Girard et al., 2011).

High temperature in all seasons and whatever the year are detrimental to primary growth. In the context of global warming, higher temperatures mean higher water stress throughout the growth season. In previous studies in the same area (Thabeetet al., 2009; Vilaet al., 2008), high temperatures in fall and winter had positive coefficients in climate/ring width relationship models for the $20^{\text {th }}$ century, which was interpreted as the favourable effect of an earlier and longer growing season. In this research, the negative correlation or non significant coefficients for temperature in these periods show that critical thresholds were probably passed: average temperatures were always high enough at the end of winter and fall to induce an early budburst or a late flush, but in fact too high and led to unfavourable stress conditions. Moreover, high temperatures at the very end of fall induce fragile very late flushes, increasing branching rate but also the risk of abortion due to frost in winter (Vennetier et al. 2011) and therefore to a waste of resources. A short photoperiod and low solar energy limit the potentially favourable effects of higher temperature in winter: whereas $\mathrm{CO}_{2}$ net uptake could occur in winter with mild weather conditions (Holst et al., 2008), the reserves used in this period to maintain a physiological activity (Damesin, 2003) are no longer available in spring. At the same time, the succession of hot periods and frost leads to reversible cavitation in the vessels, decreasing their conductivity (Cruiziat et al., 2002). This may explain why the lack of cold in winter can delay budbreak (Falusi and Calamassi, 1996).

Pre-induction of the primary growth characteristics of several flushes in buds makes primary growth mainly dependant on the global health status of trees and branch vigour at the time of bud formation. Tree vigour and health are rarely changing annually, except in case of extreme events or accidents. A healthy tree has reserves to withstand a difficult period, and a weak tree recovers only slowly even in case of good climate conditions. Such an autocorrelation is well known in ring width series (Bigler et al., 2006; Dekort et al., 1991; Schweingruber, 1996) and is logically found for primary growth in this study.

Year 2001 low values for all variables correspond to the snow break added to a long summer drought: at Font-Blanche more than $30 \mathrm{~cm}$ of heavy snow overloaded branches and damaged most of the crowns, slowing spring development. The summer drought prevented a late polycyclism to compensate for the reduced leaf area. The delayed effects of this event probably limited the crown development in year 2002 which was climatically favourable (nearly no summer drought), but shows only medium values. 
Even if 2003 was the most severe heat wave ever recorded, it was quite a good year for Aleppo pine primary growth because (1) 2002 was very favourable, preparing trees to a good following year, (2) the growth season started early thanks to a warm end of winter, and (3) the extreme temperatures started in May, when all spring flushes were already growing, water reserve in the soil allowing trees to develop normally these shoots. New needles remained very short in 2003 as half of their length is gained during summer (Vennetier at al. 2011), but trees lost most of 2 year-old needles. The impact of 2003 heat wave was mainly visible from 2004 on primary and secondary growth, due to the delayed impact of a reduced leaf area (few and short needles) and bad health condition.

As a whole, the partial or total recovery of all primary growth parameters from 2007 to 2010, as well as the very abrupt fall after 2003 , clearly showed that this trough was not due to branch ageing.

\section{2 - Fruiting}

For Aleppo pine, cone production is strongly climate- and vigour-dependent;-as no cycle of intense mast years was ever documented in literature. Our PLS models were not significant for frail and medium vigour axes. On such twigs, fruiting was too rare or absent added to high cone abortion rates, reproduction effort being mainly devoted to male flowers as already described by Thabeet et al. (2009) for Pinus silvestris and confirmed by Ne'eman et al. (2011) for Aleppo pine in Israel. Fructification success depends on the number of cones initially formed, and the development and survival rates of these cones. Cone initiation is supposed to be entirely predetermined in the terminal bud during the previous year, and then depends solely on climatic conditions and tree health status in year [n-1]. Cone development and survival depend on current year conditions and on twig ability to feed it. On the PCA plane, years 2002 and 2007 are marked out by abundant fruiting because timing was excellent: abundant precipitations before and after flowering $(2002,60 \%$ more rainfall) and low during flowering (2007, 65\% less rainfall). According to Serre (1976), male flowering begins between mid-March and April, whereas female flowering is delayed two to three weeks later in South-eastern France. Low rainfall and higher temperatures during male flowering (March-April) may allow better pollen dispersion (Pardoset al., 2003) and then, higher fructification. Year 2003 was a good illustration of excellent female flowering due to the favourable climate of previous year, followed by high abortion rates because of current year's bad conditions. Fructification collapsed from 2004 to 2005, due to both low female flowering rates induced by year [n-1] climate and abortion due to the lack of available resources (Climent et al., 2008). This reduction of the reproduction potential of Aleppo pine with severe drought is consistent with a the reduction of this potential along a spatial aridity gradient observed for this species in Tunisia by Ayari et al. (2011). A high acorn abortion rate was also observed with decreasing rainfall for Quercus ilex in a Mediterranean area (Misson et al., 2011)

\section{3 - Ring width}

When the 16-year long ring width chronology is placed in the whole chronology for Font-Blanche (1890-2008), the impact of the 2003-2007 episode is marked out by the worse trough by far ever caused by heat or drought. Whatever the study (Nicaultet al., 2001; Vilaet al., 2008) no accident except deep frosts ever led to so low indices or such a long lasting depression in Aleppo pine ring width. The impact of the most severe droughts of the $20^{\text {th }}$ century was generally rubbed out after only one year. This confirms that critical thresholds were recently passed in terms of drought intensity and repetition, and should be again at stake in the future. This threat is illustrated by the unprecedented decrease of ring width observed in Greek islands in the two last decades after repeated drought and heat waves (Sarris et al., 2011) .

\section{4 - Primary growth, global leaf area and physiology}

Globally, from 2003 to 2008, Aleppo pines branching rate was low, limiting the number of active axes, each axis bore less needles and needles were abnormally short. The potential photosynthesis was drastically cut and may be significantly hold back for several following years due to (1) the 2-3 year life span of these short needles (2) the impossibility for pines to develop new twigs on 2 and more year-old axes, so that the lack of active twigs cannot be rapidly compensated, (3) primary growth is related to tree health so that weak trees recover only progressively a normal crown development. Such a reduction of the leaf area (LAI) at stand scale with increasing aridity is confirmed for Aleppo pine by 
Vicente-Serrano et al. (2010) in Spain during the last decades, and for Quercus ilex (L.) in a rain exclusion experiment in Southern France (Misson et al., 2010). This last study showed that repeated and severe drought may changes in the relationship between photosynthetic parameters and water stress, decreasing photosynthesis efficiency. This low photosynthetic potential may contribute to a slower than expected recovery of tree growth, particularly if trees allocate most of their rare resources to recover an adequate photosynthetic biomass, and to reproduction, as observed from 2008 to 2010 in our plot. A high level of LAI deficit may also contribute to delayed forest die-back through carbon starvation after climate accidents (Allen et al., 2010).

During repeated drought and heat, Aleppo pine showed a reduced cone production for a few years. Such periods are favourable to wildfires. As Aleppo pine depends entirely on it cones to regenerate after fire, climate change may hamper its regeneration potential in the mediterranean area.

\section{5 - Conclusion and prospects}

Similar studies on other tree species are required to confirm the coherent results obtained on the impact of climate change on Pinus halepensis and $P$. sylvestris primary growth and crown development. Such results should be considered to improve functional models using leaf area indices and carbon allocation to various tree compartments (primary/secondary growth) and tree architectural development models, integrating crown development interannual variability.

\section{Acknowledgments}

We would like to thank Christian Ripert, Roland Estève, Willy Martin, Aminata N'Diaye Boucabar, Frederic Faure-Brac and Maël Grauer for their assistance in the field and laboratory work, as well as Régine Verlaque and Bruno Vila, curators from Marseille University herbarium, who contributed material to control needle length. This research was funded by the French National Research Agency (DROUGHT+ project, $\mathrm{N}^{\circ}$ ANR-06-VULN-003-04), the French Ministry for Ecology, Energy and Sustainable Development (GICC - REFORME project, ${ }^{\circ}$ MEED D4E CV05000007), the Conseil Général des Bouches-du-Rhône (CG13), ECCOREV Research Federation (FR3098), the "F-ORE-T" LTER network and Cemagref.

\section{References}

Allen, C.D., Macalady, A.K., Chenchouni, H., Bachelet, D., Mcdowell, N., Vennetier, M., Kitzberger, T., Rigling, A., Breshears, D.D., Hogg, E.H., Gonzalez, P., Fensham, R., Zhang, Z., Castro, J., Demidova, N., Lim, J.H., Allard, G., Running, S.W., Semerci, A., Cobb, N., 2010. A global overview of drought and heat-induced tree mortality reveals emerging climate change risks for forests, For. Ecol. Manag., (259) 4: 660-684.

Amato, S., Vinzi, V.E., 2003. Bootstrap-based (Q)over-cap(kh)(2) for the selection of components and variables in PLS regression, Chemom. Intell. Lab. Syst., (68) 1-2: 5-16.

Ayari, A., Moya, D., Rejeb, M.N., Ben Mansoura, A., Albouchi, A., De Las Heras, J., Fezzani, T., Henchi, B., 2011. Geographical variation on cone and seed production of natural Pinus halepensis Mill. forests in Tunisia, J. Arid Environ., (75) 5: 403-410.

Barthelemy, D., Caraglio, Y., 2007. Plant architecture: A dynamic, multilevel and comprehensive approach to plant form, structure and ontogeny, Ann. Bot., (99) 3: 375-407.

Bigler, C., Braker, O.U., Bugmann, H., Dobbertin, M., Rigling, A., 2006. Drought as an inciting mortality factor in Scots pine stands of the Valais, Switzerland, Ecosystems, (9) 3: 330-343.

Borchert, R., 1994. Induction of rehydration and bud break by irrigation or rain in deciduous trees of a tropical dry forest in Costa-Rica, Trees-Struct. Funct., (8) 4: 198-204.

Borghetti, M., Cinnirella, S., Magnani, F., Saracino, A., 1998. Impact of long-term drought on xylem embolism and growth in Pinus halepensis Mill, Trees-Struct. Funct., (12) 4: 187-195.

Borghetti, M., Magnani, F., Fabrizio, A., Saracino, A., 2004. Facing drought in a Mediterranean post-fire community: tissue water relations in species with different life traits, Acta Oecol., (25) 1-2: 67-72.

Caraglio, Y., Pimont, F., Rigolot, E., 2007. Pinus halepensis architectural analysis for fuel modelling. In: Leone, V., Loveglio, R. (eds.), Proceedings, International Workshop MEDPINE 3 - Conservation, Regeneration and 
Restoration of Mediterranean Pines and their Ecosystems, Centre International des Hautes Etudes Agronomiques Méditerranéennes Editions, Montpellier, France., 26-30 September 2005, Bari, Italy.

Climent, J., Prada, M.A., Calama, R., Chambel, M.R., De Ron, D.S., Alia, R., 2008. To grow or to seed: Ecotypic variation in reproductive allocation and cone production by young female Aleppo pine (Pinus halepensis, Pinaceae), Am. J. Bot., (95) 7: 833-842.

Cook, E.R., 1985. A time series analysis approach to tree ring standardization, The University of Arizona, Tucson (U.S.A.)

Cramer, R.D., Bunce, J.D., Patterson, D.E., Frank, I.E., 1988. Cross-validation, bootstrapping, and partial leastsquares compared with multiple-regression in conventional qsar studies, Quant. Struct-Act. Relat., (7) 1: 18-25.

Cruiziat, P., Cochard, H., Ameglio, T., 2002. Hydraulic architecture of trees: main concepts and results, Ann. For. Sci., (59) 7: 723-752.

Damesin, C., 2003. Respiration and photosynthesis characteristics of current-year stems of Fagus sylvatica: from the seasonal pattern to an annual balance, New Phytol., (158) 3: 465-475.

Debazac, E.F., 1963. Morphologie et sexualité chez les pins, Revue Forestière Française, (15): 293-303.

Dekort, I., Loeffen, V., Baas, P., 1991. Ring Width, Density and Wood Anatomy of Douglas-Fir with Different Crown Vitality, Iawa Bulletin, (12) 4: 453-465.

El Khorchani, A., Gadbin-Henry, C., Bouzid, S., Khaldi, A., 2007. The impact of drought on the growth of three forest species in Tunisia (Pinus halepensis Mill., Pinus pinea L. et Pinus pinaster Sol.), Secheresse, (18) 2: 113121.

Falusi, M., Calamassi, R., 1996. Geographic variation and bud dormancy in beech seedlings (Fagus sylvatica L), Annales Des Sciences Forestieres, (53) 5: 967-979.

Gibelin, A.L., Deque, M., 2003. Anthropogenic climate change over the Mediterranean region simulated by a global variable resolution model, Clim. Dyna., (20) 4: 327-339.

Girard, F., Vennetier, M., Ouarmim, S., Caraglio, Y., Misson, L., 2010. Polycyclism, a fundamental tree growth process, decline with recent climate change. The example of Pinus halepensis Mill. in Mediterranean France, Trees-Struct. Funct., (In press DOI 10.1007/s00468-010-0507-9).

Good, P., 1994. Permutation tests, Springer, New York (U.S.A.).

Halle, F., Oldeman, R.A.A., Tomlinson, P.B., 1978. Tropical trees and forests: an architectural analysis, Tropical trees and forests: an architectural analysis.: xvii $+441 \mathrm{pp}$.

Hesselbjerg-Christiansen, J., Hewitson, B., 2007. Regional Climate Projection. In: Climate Change 2007: The Physical Science Basis Contribution of Working Group I to the Fourth Assessment Report of the Intergovernmental Panel on Climate Change Cambridge (U.K.) and New York (U.S.A): Cambridge University Press, 2007, pp. 847-940.

Holmes, R.L., Adams, R.K., Fritts, H.C., 1986. Tree-ring chronologies of western North America: California, eastern Oregon and northern Great Bassin, with procedures used in the chronology development work, including user manuals for computer program COFECHA and ARSTAN. Laboratory of Tree-Ring Research, University of Arizona, Tucson (U.S.A.).

Holst, J., Barnard, R., Brandes, E., Buchmann, N., Gessler, A., Jaeger, L., 2008. Impacts of summer water limitation on the carbon balance of a Scots pine forest in the southern upper Rhine plain, Agric. For. Meteorol., (148) 11: 1815-1826.

Jalkanen, R., Aalto, T., Kurkela, T., 1994. The Use of Needle-Trace Method (Ntm) in Retrospectively Detecting Lophodermella Needle-Cast Epidemic, Eur. J. For. Pathol, (24) 6-7: 376-385.

Jalkanen, R., Aalto, T., Kurkela, T., 1998. Revealing past needle density in Pinus spp, Scand. J. For. Res., (13) 3 : $292-296$.

Le Houerou, H.N., 2005. The Isoclimatic Mediterranean Biomes: Bioclimatology, Diversity and Phytogeography Vol 1 and 2, Copymania Publication, Montpellier (France).

Masotti, V., Barthelemy, D., Mialet, I., Sabatier, S., Caraglio, Y., 1995. Study on the effect of the environment on the growth, branching and architecture of the atlas cedar, Cedrus atlantica (Endl) Manetti ex Carriere, Architecture of Forest and Fruit Trees, 74: 175-189.

Meehl, G.A., Tebaldi, C., 2004. More intense, more frequent, and longer lasting heat waves in the 21 st century, Science, (305) 5686: 994-997.

Météo-France, 2011. Data from Aubagne, Gémenos, Cuges-les-pins and Roquefort-la-Bédoule stations (National Meteorological Survey Network).

Météofrance, 2009. Données météorologiques des stations d'Aubagne, Gémenos, Cuges-les-pins(data from the National Meteorological Survey Network).

Misson, L., Degueldre, D., Collin, C., Rodriguez, R., Rocheteau, A., Ourcival, J.M., Rambal, S., 2011. Phenological responses to extreme droughts in a Mediterranean forest, Glob. Change Biol., (17) 2: 1036-1048.

Misson, L., Limousin, J.M., Rodriguez, R., Letts, M.G., 2010. Leaf physiological responses to extreme droughts in Mediterranean Quercus ilex forest, Plant Cell Environ., (33) 11: 1898-1910. 
Nahal, I., 1962. Le Pin d'Alep (Pinus halepensis Mill.) Étude taxonomique, phytogéographique, écologique et sylvicole, Annales de l'École des Sciences de la Nature, des eaux et des Forêts Nancy (France).

Ne'eman, G., Goubitz, S., Werger, M.J.A., Shmida, A., 2011. Relationships between tree size, crown shape, gender segregation and sex allocation in Pinus halepensis, a Mediterranean pine tree, Ann. Bot., (108) 1: 197206.

Nemenyi, P.B., 1963. Distribution-free multiple comparisons, Princeton University Press, Princeton.

Nicault, A., Rathgeber, C., Tessier, L., Thomas, A., 2001. Intra-annual variations of radial growth and ring structure, Ann. For. Sci., (58) 7: 769-784.

Ogaya, R., Peñuelas, J., Martínez-Vilalta, J., Mangirón, M., 2003. Effect of drought on diameter increment of Quercus ilex, Phillyrea latifolia, and Arbutus unedo in a holm oak forest of NE Spain, For. Ecol. Manag., (180) 1-3: 175-184.

Orshan, G., 1989. Plant pheno-morphological studies in Mediterranean type ecosystems, Dordrecht (Netherlands), Kluwer.

Pardos, M., Climent, J., Gil, L., Pardos, J.A., 2003. Shoot growth components and flowering phenology in grafted Pinus halepensis Mill, Trees-Struct. Funct., (17) 5: 442-450.

R Development Core Team, 2004. R: A language and environment for statistical computing. R Foundation for Statistical Computing. Vienna (Austria)

Rathgeber, C., Blanc, L., Ripert, C., Vennetier, M., 2004. Modélisation de la croissance en hauteur du pin d'Alep (Pinus halepensis Mill.) en région méditerranéenne française, Ecol. Mediterr., (30) 2: 205-218.

Rathgeber, C., Nicault, A., Guiot, J., Keller, T., Guibal, F., Roche, P., 2000. Simulated responses of Pinus halepensis forest productivity to climatic change and $\mathrm{CO} 2$ increase using a statistical model, Glob Planet Change, (26) 4: 405-421.

Rathgeber, C.B.K., Misson, L., Nicault, A., Guiot, J., 2005. Bioclimatic model of tree radial growth: application to the French Mediterranean Aleppo pine forests, Trees-Struct. Funct., (19) 2: 162-176.

Sabatier, S., Baradat, P., Barthelemy, D., 2003. Intra- and interspecific variations of polycyclism in young trees of Cedrus atlantica (Endl.) Manetti ex. Carriere and Cedrus libani A. Rich (Pinaceae), Ann. For. Sci., (60) 1: 1929.

Sardans, J., Peñuelas, J., 2007. Drought changes the dynamics of trace element accumulation in a Mediterranean Quercus ilex forest, Environ. Pollut., (147) 3: 567-583.

Sarris, D., Christodoulakis, D., Korner, C., 2011. Impact of recent climatic change on growth of low elevation eastern Mediterranean forest trees, Clim. Change, (106) 2: 203-223.

Schweingruber, F.H., 1996. Tree rings and environment: Dendroecology, Paul Haupt Publishers, Bern (Swizerland).

Serre, F., 1976. Les rapports de la croissance et du climat chez le pin d'Alep (Pinus halepensis (Mill)) II L'allongement des pousses et des aiguilles, et le climat Discussion Générale, Oecologia Plantarum, (11) 3: 201224.

Thabeet, A., Vennetier, M., Gadbin-Henry, C., Denelle, N., Roux, M., Caraglio, Y., Vila, B., 2009. Response of Pinus sylvestris L. to recent climate change in the French Mediterranean region, Trees-Struct. Funct., (28) 4 : 843-853

Thioulouse, J., Chessel, D., Doledec, S., Olivier, J.M., 1997. ADE-4: A multivariate analysis and graphical display software, Statistics and Computing, (7) 1: 75-83.

Vennetier, M., Girard, F., Didier, C., Ouarmim, S., Ripert, C., Estève, R., Martin, W., N'diaye, A., Misson, L., 2011. Adaptation phénologique du pin d'Alep au changement climatique, Forêt Méditerranéenne, (32) 2: 151166.

Vennetier, M., Hervé, J.C., 1999. Short and long term evolution of Pinus halepensis (Mill.) height growth in Provence (France) and its consequences for timber production. In: EFI proceedings, Joensuu: EFI \& ECOFOR, 1999 , vol 27, pp. $253-265$.

Vennetier, M., Ripert, C., 2009. Forest flora turnover with climate change in the Mediterranean region: A case study in Southeastern France, For. Ecol. Manag., (258): S56-S63.

Vennetier, M., Ripert, C., 2010. Climate change impact on vegetation: lessons from an exceptionally hot and dry decade in South-eastern France. In: Climate Change and variability, Rijeka, Croatia: Sciyo, 2010, pp. 225-241.

Vennetier, M., Ripert, C., Brochiero, F., Rathgeber, C., Nassif, Y., Chandioux, O., 2010. Evaluation de la croissance du pin d'Alep en région méditerranéenne française, Revue Forestière Française, (LXXII) 5: 503-524.

Vennetier, M., Ripert, C., Maillé, E., Blanc, L., Torre, F., Roche, P., Tatoni, T., Brun, J.-J., 2008. A new bioclimatic model calibrated with flora for Mediterranean forested areas, Ann. For. Sci., (65) 711.

Vennetier, M., Vila, B., Liang, E.Y., Guibal, F., Thabeet, A., Gadbin-Henry, C., 2007. Impact of climate change on pine forest productivity and on the shift of a bioclimatic limit in a Mediterranean area., Options Méditerranéennes, Série A, ( ) 75: 189-197.

Vicente-Serrano, S.M., Lasanta, T., Gracia, C., 2010. Aridification determines changes in forest growth in Pinus halepensis forests under semiarid Mediterranean climate conditions, Agric. For. Meteorol., (150) 4: 614-628. 
Vila, B., Vennetier, M., Ripert, C., Chandioux, O., Liang, E., Guibal, F., Torre, F., 2008. Has global change induced opposite trends in radial growth of Pinus sylvestris and Pinus halepensis at their bioclimatic limit? The example of the Sainte-Baume forest (south-east France). Ann. For. Sci., (65) 709.

Wold, S., 1995. PLS for multivariate linear modelling. In: Chemometric methods in molecular design, Weinheim (Germany), 1995, pp. 195-218.

Zaitchik, B.F., Macalady, A.K., Bonneau, L.R., Smith, R.B., 2006. Europe's 2003 heat wave: A satellite view of impacts and land-atmosphere feedbacks, Int. J. Clim., (26) 6: 743-769. 